\title{
A Novel Nitrite Biosensor Based on Gold Dendrites with Egg White as Template
}

\author{
Yaping He, Dawei Zhang, Sheying Dong, and Jianbin ZhENG ${ }^{\dagger}$ \\ Institute of Analytical Science/Shaanxi Provincial Key Laboratory of Electroanalytical Chemistry, \\ Northwest University, Xi'an, Shaanxi 710069, P. R. China
}

\begin{abstract}
Gold dendrites (AuD) were synthesized with egg white as the soft template and a novel nitrite $\left(\mathrm{NO}_{2}^{-}\right)$biosensor was fabricated by assembly of a myoglobin (Mb)-L-cysteamine (Cys)-AuD biological hybrid. The results of Fourier transform infrared spectra and UV-visible spectra indicated that $\mathrm{Mb}$ retained its original structure in the resulting Mb-Cys-AuD. Electrochemical investigation of the biosensor showed a pair of well-defined, quasi-reversible redox peaks with $E_{\mathrm{pa}}=-0.314 \mathrm{~V}$ and $E_{\mathrm{pc}}=-0.344 \mathrm{~V}$ ( $v s . \mathrm{SCE}$ ) in $0.1 \mathrm{M}, \mathrm{pH} 7.0$ sodium phosphate buffered saline at the scan rate of $200 \mathrm{mV} / \mathrm{s}$. The transfer rate constant $\left(k_{\mathrm{s}}\right)$ was $1.49 \mathrm{~s}^{-1}$. The Mb-Cys-AuD showed a good electrochemical catalytic response for the reduction of $\mathrm{NO}_{2}^{-}$, with the linear range from 0.5 to $400 \mu \mathrm{M}$ and the detection limit of $0.3 \mu \mathrm{M}(S / N=3)$. The apparent Michaelis-Menten constant $\left(K_{\mathrm{M}}^{\mathrm{app}}\right)$ was estimated to be $0.2 \mathrm{mM}$. Therefore, the assembled bio-hybrid as a novel matrix opened up a further possibility for study on the design of enzymatic biosensors with potential applications.
\end{abstract}

(Received November 27, 2011; Accepted January 31, 2012; Published Apirl 10, 2012)

\section{Introduction}

Biocompatible materials, such as natural biomaterials, bio-hybrid, biopolymers and some nanomaterials, can provide a favorable microenvironment for redox proteins to realize their direct electrochemistry; and with them one can fabricate excellent

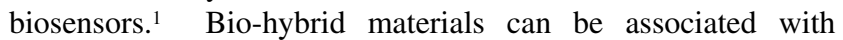
materials that have in common a biological component and an inorganic component. ${ }^{2}$ While they can exhibit very different structures and unique properties mainly depending on the nature of the biological system. Bio-hybrid materials may have important advantages over conventional biomaterials including improved cellular integration, the potentially are more straightforward in vivo applicability, and they are able to effectively remodel their materials structure with time. ${ }^{3}$

Gold $(\mathrm{Au})$ plays a special role in nanoscience and nanotechnology, due to the fact that $\mathrm{Au}$ is the most stable noble metal at the nano-scale. Thus, the designers of any nano-device requiring metallic components are likely to conside $\mathrm{Au}^{4}{ }^{4}$ The excellent biocompatibility, conductivity and catalytic properties also make $\mathrm{Au}$ candidate to amplify the electrode surfaces, to enhance the electron transfer between redox centers in proteins, and to act as catalyst to facilitate electrochemical reactions. ${ }^{5} \mathrm{Au}$ offers unique surface chemistry properties that allow it to be used as a desired platform on which to self-assemble layers of organic molecules, usually bound to the gold by sulfur atoms. ${ }^{6}$ The abundant thiol and amino groups of biomaterials, make the fabrication of Au-associated bio-hybrids become a hot point for the development of novel biosensors.

Wet chemistry technique based on chemical reactions in solution is the most widely used procedure for the synthesis of

$\dagger$ To whom correspondence should be addressed.

E-mail: zhengjb@nwu.edu.cn
nano-Au with a wide range of sizes, shapes and dielectric environments. The average particle diameter and surface morphology, which are the most important parameters when applying the nanoparticles to biosensing, can be controlled experimentally in an easy manner by adjusting the preparation conditions. ${ }^{4}$ Conjugation of nano-Au with other nanomaterials and biomolecules is an attractive research area within nanobiotechnology. ${ }^{7}$ Peptide functionalized Au surfaces that connect the highly organized structure of a thiol self-assembled monolayers (SAMs) on Au with biologically relevant structural elements were prepared. ${ }^{8} \mathrm{Au}$ of dendrimer-like structures (AuD) was synthesized by a one-pot route, wherein a novel surfactant solution was used as reducing agent and assembling agent. ${ }^{9}$ The dendritic structures have relatively large surface areas, which is beneficial for the immobilization of biomaterials. ${ }^{10}$ Here, a facile wet-chemical method for the synthesis of $\mathrm{AuD}$ was reported. Biomaterial egg white was used as the template, which provided two key elements of dendritic forms: the branching structures and the erratic winding travels of individual branches.

As well known, the major proteins of the egg white are ovalbumin, lysozyme, and ovotransferrin. ${ }^{11}$ Thus, egg white can act as a macromolecular polymer, ${ }^{12}$ and its excellent foaming and gelling properties ${ }^{13}$ allow it to be used as surfactant. The presence of egg white in the synthesis of nanomaterials leads to a different progression of the nano formation. ${ }^{11}$ Using cheap, non-toxic and environmentally benign egg white protein, $\mathrm{CuFe}_{2-}{ }_{\mathrm{x}} \mathrm{Cr}_{\mathrm{x}} \mathrm{O}_{4} \quad(0 \leq x \leq 1)$ nanopowders were successfully synthesized with metal nitrates. ${ }^{14}$ Platelike $\mathrm{CeO}_{2}$ nanoparticles was synthesized in an aqueous medium by a simple, cost-effective, and environmentally friendly method using cerium(III) acetate hydrate and freshly extracted egg white (ovalbumin). ${ }^{15}$ By using $\mathrm{Co}^{2+}$ and $\mathrm{Co}^{3+}$ salts, and freshly extracted ovalbumin, $\mathrm{Co}_{3} \mathrm{O}_{4}$ nanocrystals have been synthesized successfully. ${ }^{16}$ However, to our knowledge, there was no similar 
application in the synthesis of nano-Au based on egg white as the soft biotemplate reported in the literature.

The aim of the present work are to synthesize AuD by employing egg white as the soft biotemplate; and this material was employed to fabricate a nitrite $\left(\mathrm{NO}_{2}{ }^{-}\right)$biosensor by self-assembly technique. The electrochemical behavior of myoglobin $(\mathrm{Mb})$ and its electrocatalysis towards nitrite $\left(\mathrm{NO}_{2}^{-}\right)$ in the proposed biosensor are further investigated.

\section{Experimental}

\section{Reagents}

Bovine myoglobin $\left(\mathrm{Mb}, M_{\mathrm{W}} 17800\right)$, chloroauric acid tetrahydrate $\left(\mathrm{HAuCl}_{4} \cdot 4 \mathrm{H}_{2} \mathrm{O}\right)$, 1-ethyl-3-(3-dimethylaminopropyl) carbodiimide (EDC) and $\mathrm{N}$-hydroxysuccinimide (NHS) were purchased from Sigma (St. Louis, USA). Cys was from Bailingwei Co., Ltd. (Beijing, China). Eggs were obtained from the local market. A $0.1 \mathrm{M}$ sodium phosphate buffered saline (PBS) with various $\mathrm{pH}$ values were prepared by mixing stock standard solutions of $\mathrm{Na}_{2} \mathrm{HPO}_{4}$ and $\mathrm{KH}_{2} \mathrm{PO}_{4}$ and adjusting the $\mathrm{pH}$ value with $0.1 \mathrm{M} \mathrm{H}_{3} \mathrm{PO}_{4}$ or $\mathrm{NaOH}$.

\section{Apparatus}

Cyclic voltammetry (CV) and electrochemical impedance spectroscopy (EIS) were carried out on a CHI 660D electrochemical workstation (Shanghai CH Instrument Co. Ltd., China). A traditional three-electrode system was used with an Mb-modified electrode as working electrode, a platinum wire as auxiliary electrode and a saturated calomel electrode (SCE) as reference electrode. Thus, all the potentials reported in this work had been measured versus SCE reference electrode. Fourier transform infrared (FTIR) spectra were recorded on $\mathrm{KBr}$ disk using a Nicolet 380 FTIR spectrometer (Thermo Electron Corp., USA). UV-visible spectra were obtained on a Cary 50 probe UV-visible spectrophotometer (Varian, Australia). Scanning electron microscopy (SEM) was done with a JSM-6700F scanning electron microscope (Japan Electron Company, Japan). All the tested solutions were purged with highly purified nitrogen for at least $20 \mathrm{~min}$ prior to a series of voltammetric experiments and were maintained under nitrogen atmosphere during the measurements. All the electrochemical experiments were conducted at room temperature $\left(25 \pm 2^{\circ} \mathrm{C}\right)$.

\section{Preparation of the AuD}

AuD was prepared as follows: $1 \mathrm{~mL}$ of $\mathrm{HAuCl}_{4}$ solution (w/w, $1 \%$ ) and $5 \mathrm{~mL}$ of freshly extracted egg white were added into $100 \mathrm{~mL}$ flask. Then, the solution was heated until boiling, and then $5 \mathrm{~mL}$ of sodium citrate solution (w/w, 1\%) was slowly added, while stirring vigorously. There are large degeneration proteins floating at the surface of the solution and one should immediately filtrate. The wine red solution should be kept continuous boiling for $30 \mathrm{~min}$; then, it should be allowed to cool down. The $\mathrm{AuD}$ was prepared and stored at $4{ }^{\circ} \mathrm{C}$ for use. For controlled trials, conventional AuNPs were prepared as follows: $1 \mathrm{~mL}$ of $\mathrm{HAuCl}_{4}$ solution (w/w, 1\%) was added into $100 \mathrm{~mL}$ flask; then the mixture heated until the solution began boiling, next, $5 \mathrm{~mL}$ of sodium citrate solution (w/w, 1\%) was quickly added while stirring vigorously. After continuous boiling for $30 \mathrm{~min}$, the mixture was allowed to cool down. AuNPs were prepared.

\section{Preparation of the Mb modified electrode}

A DL-180 ultrasonic cleaning machine $(35 \mathrm{kHz}$, Zhejiang Haitian Electron Instrument Factory, China) was used to dissolve solutes and form homogeneous solutions. GCE of 3-mm diameter, before use, was first polished to mirror-like finish with 1.0, 0.3 and $0.05 \mu \mathrm{m} \mathrm{Al}_{2} \mathrm{O}_{3}$ slurry on a polish cloth, and then rinsed with double-distilled water, then sonicated in ethanol and double-distilled water for $5 \mathrm{~min}$, each. A $50-\mu \mathrm{L}$ volume of $\mathrm{AuD}$ and $30 \mu \mathrm{L}$ of $0.1 \mathrm{M}$ Cys were mixed for $30 \mathrm{~min}$. Then, $50 \mu \mathrm{L}$ of $5 \mathrm{mM}$ EDC and $5 \mathrm{mM}$ NHS mixture was added into the solution, and $40 \mu \mathrm{L}$ of $20 \mathrm{mg} / \mathrm{mL} \mathrm{Mb}$ was added; the mixture are shaken in a rocking incubator at $37 \pm 0.2^{\circ} \mathrm{C}$ mixed for $24 \mathrm{~h}$. Fianlly $10 \mu \mathrm{L}$ of the mixture was cast onto the surface of the bare GCE by using a syringe to prepare Mb-Cys-AuD/GCE. Without use, the biosensor was stored at $4{ }^{\circ} \mathrm{C}$ in a refrigerator. For controlled trial, the Mb-Cys-AuNPs/GCE was fabricated with AuNPs other than AuD under the same process mentioned above; the Mb-Cys-AuD/GCE was prepared by in situ assembly as follows: $10 \mu \mathrm{L}$ of $\mathrm{AuD}$ was casted onto the surface of the bare GCE by using a syringe to prepare AuD/GCE; then, immersed into $0.1 \mathrm{M}$ Cys for $30 \mathrm{~min}$. The Cys-AuD/GCE was washed with pure water, then, $10 \mu \mathrm{L}$ of $4 \mathrm{mg} / \mathrm{mL}$ of $\mathrm{Mb}$ containing $5 \mathrm{mM}$ EDC and $5 \mathrm{mM}$ NHS in PBS was casted onto the surface of the Cys-AuD/GCE. Thus, in situ assembled $\mathrm{Mb}-\mathrm{Cys}-\mathrm{AuD} / \mathrm{GCE}$ was prepared.

\section{Results and Discussion}

Strategy for the fabrication of Au and the Mb-Cys-AuD bio-hybrid Diffusion limited aggregation processes produce complicated shapes qualitatively similar to real dendrites. ${ }^{17}$ The formatted $\mathrm{Au}$ nanoseeds at the origin of a lattice were self-assembled on the amino groups $\left(\mathrm{NH}_{2}\right)$ of the thermal denaturation protein through $\mathrm{Au}-\mathrm{NH}$ bonds. Other $\mathrm{Au}$ nanoseeds were allowed to walk at random, just as diffusion from far away until they arrived at one of the lattice sites adjacent to the occupied site. Then they were stopped; another Au nanoseeds were launched and halted when adjacent to the two occupied sites; the sequence was repeated. An indefinitely large cluster may be formed in this way. A typical structure produced on a two-dimensional lattice is dendrimer-like nano Au.

Scheme 1 illustrats the general design strategy for the Mb-Cys-AuD bio-hybrid. Cys served as a linker between $\mathrm{Mb}$ and AuD. The self-assembly process of thiol groups $(\mathrm{SH})$ at the terminal of Cys interacted with $\mathrm{AuD}$ to form Cys-AuD. The coupling reaction of $\mathrm{NH}_{2}$ at the other terminal of Cys with carboxyl group of $\mathrm{Mb}$ strengthened the immobilization of $\mathrm{Mb}$ in the Mb-Cys-AuD. AuD formed as a tree, and $\mathrm{Mb}$ atoms were like apples on the tree. Cys worked as the carpopodium to keep $\mathrm{Mb}$ on AuD tightly. The strong interest in assembly based on $\mathrm{SH}$ with nano-Au is always due to the following aspects: ${ }^{18}$ (1) they can offer insulating barriers between an electrode and a redox couple to study the long-range electron transfer process; (2) they can fabricate supermolecule assemblies with tailored architecture and properties for creating selective voltammetric detectors and measuring very fast electron transfer kinetics. With the formation of $\mathrm{SH}-\mathrm{Au}, \mathrm{Cys}-\mathrm{AuD}$ biocomposite, which provide a favorable matrix for the immobilization of $\mathrm{Mb}$, were formed.

\section{Characterization of the $A u D$ and the $M b-C y s-A u D$}

The morphology of AuD observed by SEM is shown in Fig. 1. In Fig. 1A, AuD show the branching structures and the erratic winding travels of individual branches, which were in conformity with dendritic structure. SEM with high magnification showed a dotted pattern with diameters of $60-100 \mathrm{~nm}$ (as shown in Fig. 1B), proving that the dendrite consists of a single crystal, 


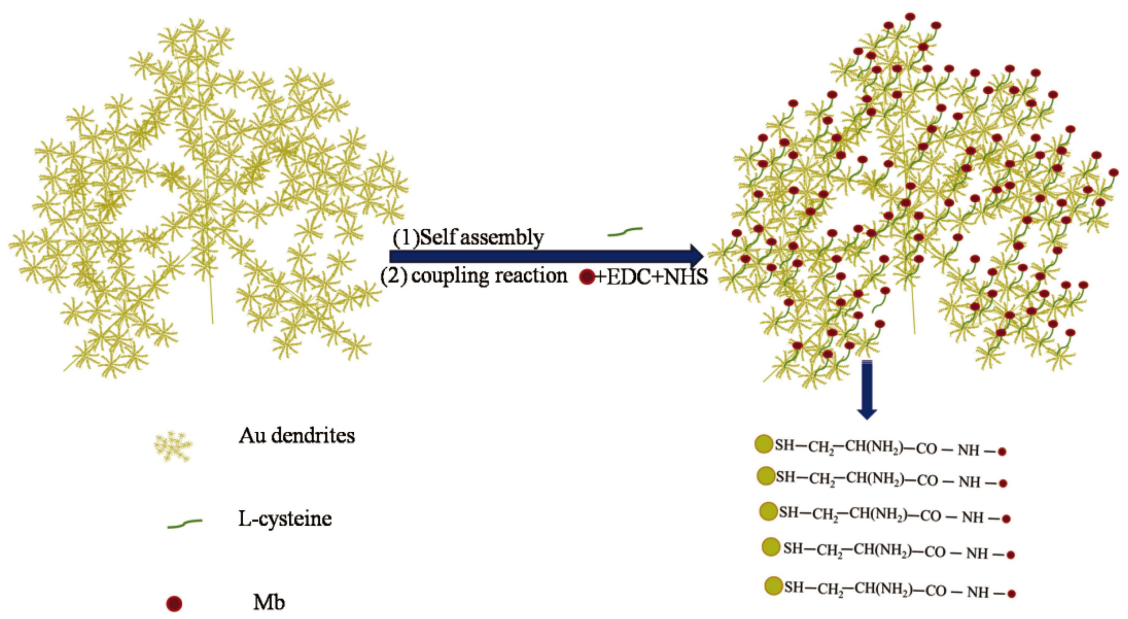

Scheme 1 Scheme of the assembly process of the Mb-Cys-AuD/GCE.
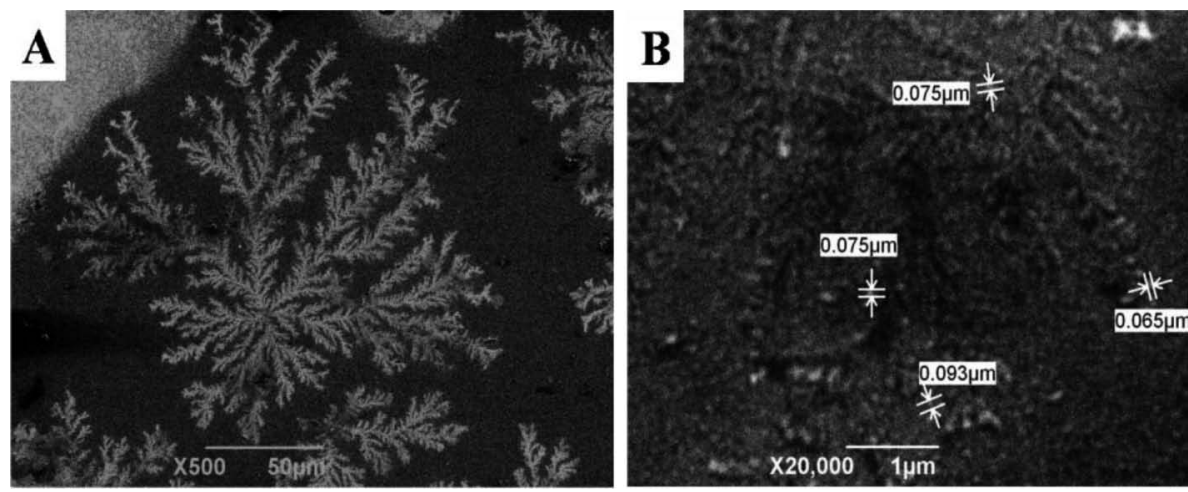

Fig. 1 SEM images of AuD with low (A) and high (B) magnification.
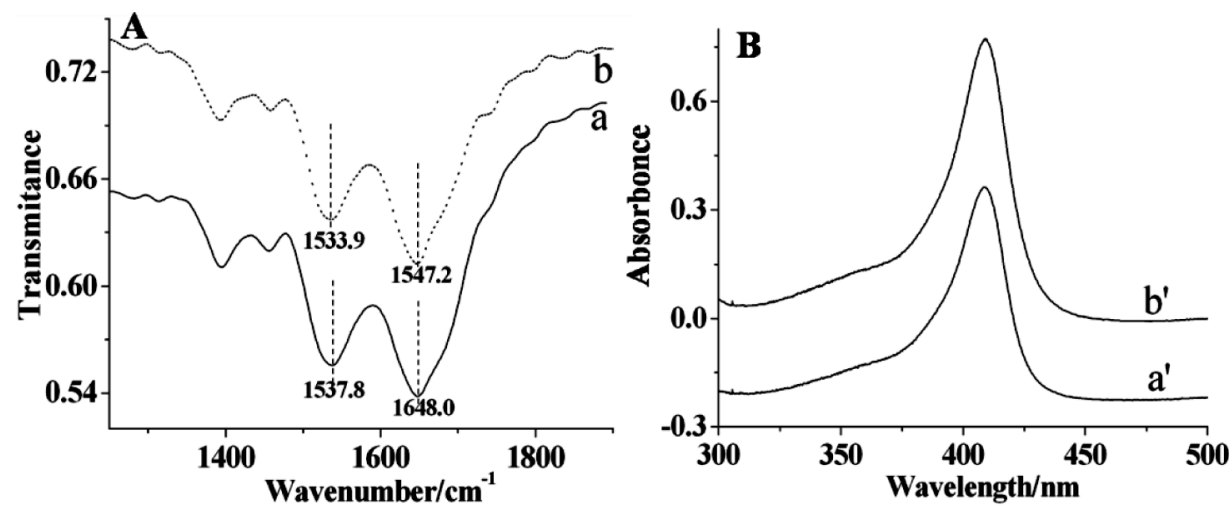

Fig. 2 (A) FTIR spectra of $\mathrm{Mb}$ (a) and the Mb-Cys-AuD film (b). (B) UV-vis absorption spectra of $0.3 \mathrm{mg} / \mathrm{mL} \mathrm{Mb}$ in PBS $\left(\mathrm{a}^{\prime}\right)$ and in the solution of Mb-Cys-AuD mixture ( $\left.\mathrm{b}^{\prime}\right)$. The light path length, $1 \mathrm{~cm}$.

not an agglomeration of small distinct nanoparticles.

FTIR spectra and UV-visible spectra were used to characterize the Mb-Cys-AuD. FTIR spectroscopy was used to monitor the secondary structure conformations of polypeptide chain of the Mb-Cys-AuD. In Mb, amide I band $\left(1700-1600 \mathrm{~cm}^{-1}\right)$ was caused by $\mathrm{C}=\mathrm{O}$ stretching vibration of peptide linkages and amide II band $\left(1620-1500 \mathrm{~cm}^{-1}\right)$ was attributed to the combination of $\mathrm{N}-\mathrm{H}$ in plane bending and $\mathrm{C}-\mathrm{N}$ stretching vibrations of the peptide groups. ${ }^{19}$ If $\mathrm{Mb}$ is denatured, the intensities and shape of amide I and II band will diminish or even disappear. As shown in Fig. 2A, the spectrum of free $\mathrm{Mb}$ (a) was similar to that of $\mathrm{Mb}$ in the Mb-Cys-AuD (b), which suggests that $\mathrm{Mb}$ retains the essential feature of its native structure in the Mb-Cys-AuD.

UV-visible Soret absorption band of $\mathrm{Mb}$ may provide some information on the conformational integrity of the protein and on the possible denaturation or the conformational change of heme region. $\mathrm{Mb}$ dissolved in PBS had the Soret band at 

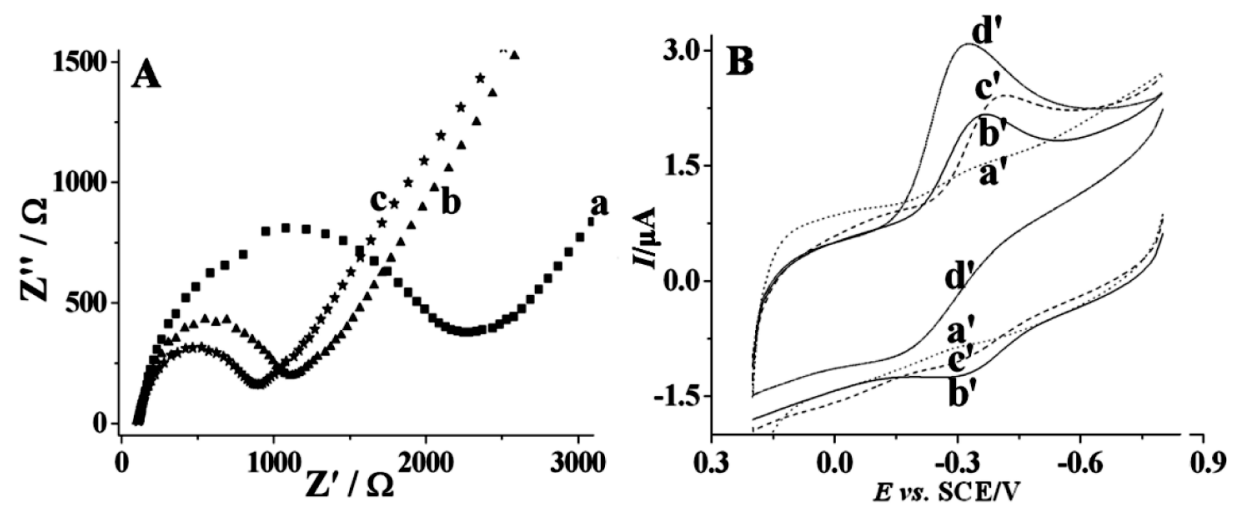

Fig. 3 (A) EIS plots for bare GCE (a), the Mb-Cys-AuD/GCE (b), and the AuD/GCE (c) in a solution of $1 \mathrm{mM}\left[\mathrm{Fe}(\mathrm{CN})_{6}\right]^{3-14}+0.1 \mathrm{M} \mathrm{KCl}$ as the supporting electrolyte. The frequencies were swept from $10^{5}$ to $10^{-2} \mathrm{~Hz}$. (B) CVs of the bare GCE (a'), Mb-Cys-AuD/GCE (b'), in situ assembled Mb-Cys-AuD/GCE ( $\left.\mathrm{c}^{\prime}\right)$ and Mb-Cys-AuNPs/GCE (d') in $\mathrm{N}_{2}$ saturated PBS at the scan rate of 200 $\mathrm{mV} / \mathrm{s}$.

$408.9 \mathrm{~nm}\left(\mathrm{a}^{\prime}\right)$, while in the Mb-Cys-AuD the Soret band was appeared at $409.2 \mathrm{~nm}\left(\mathrm{~b}^{\prime}\right)$ as shown in Fig. 2B. The difference of $\mathrm{Mb}$ and the $\mathrm{Mb}-\mathrm{Cys}-\mathrm{AuD}$ was less than $1 \mathrm{~nm}$, indicating that $\mathrm{Mb}$ in the Mb-Cys-AuD had the microenvironment similar to the native state of Mb-heme in PBS.

Ferricyanide was chosen as a marker of electrochemical impedance spectroscopy (EIS) to further investigate the behaviors of the Mb-Cys-AuD. At the bare GCE, the redox process of $\left[\mathrm{Fe}(\mathrm{CN})_{6}\right]^{3-14-}$ probe showed an electron transfer resistance of about $182.0 \Omega$ (curve a in Fig. 3A). When the GCE was modified with AuD (curve c in Fig. 3A), the diameter of the semicircle reduced to $110.5 \Omega$, suggesting that AuD has an excellent electrical conductivity. When $\mathrm{Mb}$ was immobilized on AuD (curve b in Fig. 3A), the electron transfer resistance was slightly increased to $120.8 \Omega$. Owing to the dielectric behavior of enzyme molecules for interfacial electron transfer processes, the higher enzyme coverage will result in a higher barrier for the interfacial electron transfer. These data confirmed that $\mathrm{Mb}$ had been successfully immobilized on $\mathrm{AuD}$ and that it blocked the electron exchange between the redox probe and the electrode.

In $\mathrm{N}_{2}$ saturated 0.1 M PBS ( $\mathrm{pH} 7.0$ ), the bare GCE had no peaks (shown in Fig. 3B, curve $\mathrm{a}^{\prime}$ ). The in situ assembled Mb-Cys-AuD/GCE only showed one cathode peak at $-0.409 \mathrm{~V}$ (shown in Fig. 3B curve $\mathrm{c}^{\prime}$ ) due to the fact that, when AuD was casted on the electrode surface, some of the binding sites towards Cys were lost. A chain effect was shown. The assembly amount of Cys decreased, and sequentially, the amount of $\mathrm{Mb}$ attached to the proposed electrode was smaller than that of the assembled Mb-Cys-AuD bio-hybrid. Though a much bigger cathode peak at -0.329 was shown at the Mb-Cys-AuNPs/GCE, no anodic peak appeared. A pair of asymmetric redox peaks appeared in the Mb-Cys-AuD/GCE (Fig. 3B, curve b'), which was attributed to the redox process of heme $\mathrm{Fe}(\mathrm{III}) / \mathrm{Fe}(\mathrm{II})$ couple. The above electrochemical performance of different electrodes indicated that $\mathrm{AuD}$ could provide a favorable microenvironment for $\mathrm{Mb}$ to retain its natural structure and to realize its direct electrochemistry. AuD plays important roles to facilitate the electron transfer from $\mathrm{Mb}$ the synergistic effect of Mb-Cys-AuD which is useful to amplify the signal output.

\section{Direct electrochemistry of $M b$}

The direct electrochemistry of $\mathrm{Mb}$ in the Mb-Cys-AuD/GCE was studied by cyclic voltammetry (CV). Cyclic voltammograms (CVs) of $\mathrm{Mb}$ at the Mb-Cys-AuD/GCE with different scan rates

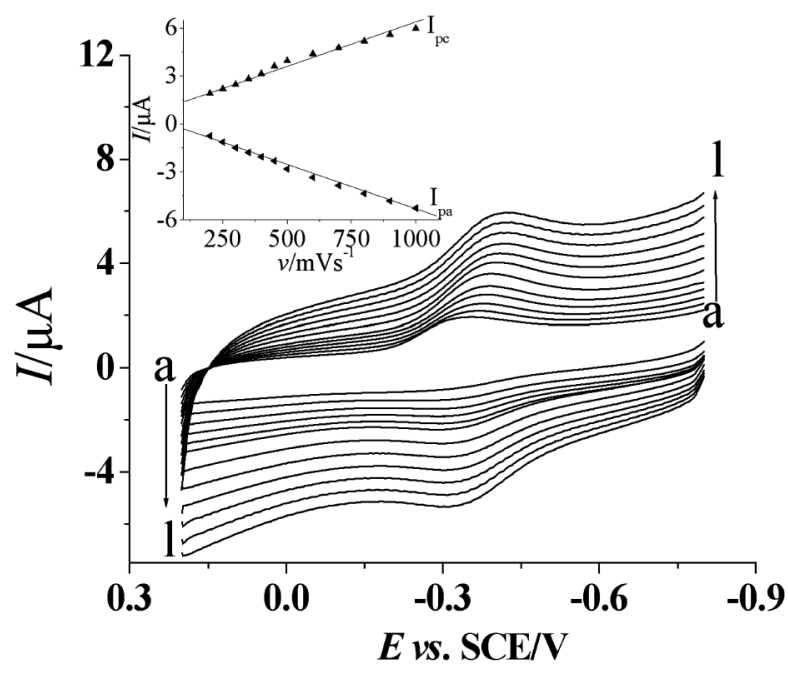

Fig. $4 \mathrm{CVs}$ of the Mb-Cys-AuD/GCE in $\mathrm{N}_{2}$ saturated PBS with different scan rates. From a to $1: 200,250,300,350,400,450,500$, $600,700,800,900,1000 \mathrm{mV} / \mathrm{s}$. Inset: the relationship between cathodic and anodic peak current with scan rate $v$.

are shown in Fig. 4. The modified electrode showed a pair of well-defined, quasi-reversible redox peaks with $E_{\mathrm{pa}}=-0.314 \mathrm{~V}$ and $E_{\mathrm{pc}}=-0.344 \mathrm{~V}$ (vs. SCE) in PBS (0.1 M, pH 7.0) with the formal potential $E^{0^{\prime}}=-0.329 \mathrm{~V}$. The value of $E^{0^{\prime}}$ was similar to Mb-mesopores cellular foams/GCE. ${ }^{20}$ The peak-to-peak separation $\Delta E_{\mathrm{p}}$ was $30 \mathrm{mV}$ and about 1 ratio of cathodic to anodic current intensity at the scan rate of $200 \mathrm{mV} / \mathrm{s}$, indicating that the direct electron transfer for $\mathrm{Mb}-\mathrm{Fe}(\mathrm{III}) / \mathrm{Fe}$ (II) was nearly reversible. The redox process of $\mathrm{Mb}$ at the $\mathrm{Mb}-\mathrm{Cys}-\mathrm{AuD} / \mathrm{GCE}$ gave roughly symmetric anodic and cathodic peaks at relative slow scan rates. When the scan rate increased, the redox potentials $\left(E_{\mathrm{pa}}\right.$ and $\left.E_{\mathrm{pc}}\right)$ of $\mathrm{Mb}$ hardly shift. Meanwhile, the redox peak current changed linearly (inset, Fig. 4): $I_{\mathrm{pa}}=$ $1.08-5.1 \times 10^{-3} v, \quad r=0.9891 ; \quad I_{\mathrm{pc}}=0.21-5.7 \times 10^{-3} v, \quad r=$ 0.9970 . This indicated that the electron transfer process for $\mathrm{Mb}$ at the Mb-Cys-AuD/GCE was a surface-confined mechanism in the above-mentioned potential range, manifesting the characteristics of a thin-layer surface-controlled electrochemical process. 


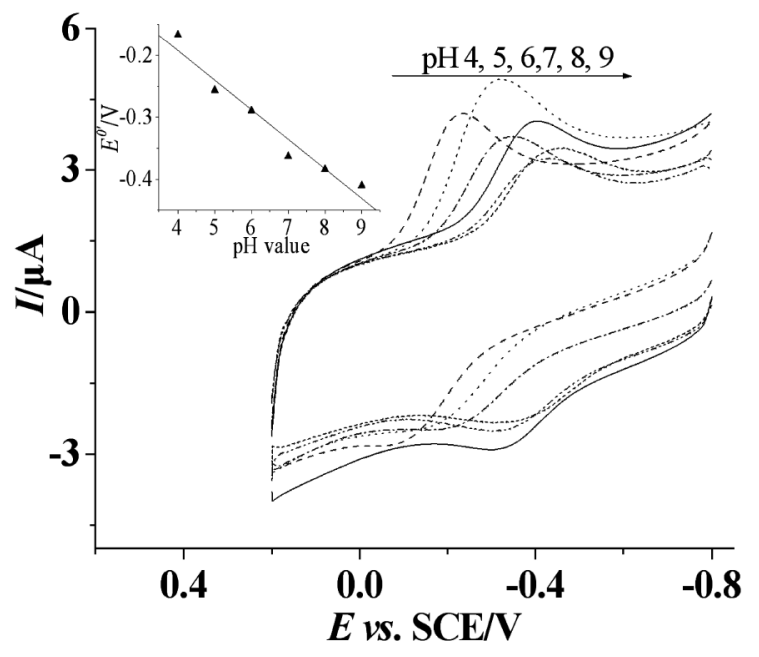

Fig. 5 Influence of the $\mathrm{pH}$ value on the $\mathrm{CV}$ s of the $\mathrm{Mb}-\mathrm{Cys}-\mathrm{AuD} / \mathrm{GCE}$. $\mathrm{pH}$ values (from left to right): 4.0, 5.0, 6.0, 7.0, 8.0, 9.0. Inset: the relationship between and $\mathrm{pH}$. Scan rate, $500 \mathrm{mV} / \mathrm{s}$.

The anodic and cathodic peak potentials were linearly dependent on the logarithm of the scan rates $(n)$ with slopes of $-2.3 R T / a n F$ and $2.3 R T /(1-a) n F$, respectively. ${ }^{1}$ Hence, the charge-transfer coefficient $a$ was calculated as 0.53 . Heterogeneous electron transfer rate constant $\left(k_{\mathrm{s}}\right)$ was further estimated according to the following equation: ${ }^{21}$

$$
\log k_{\mathrm{s}}=a \log (1-a)+(1-a) \log a-\log (R T / n F v)-
$$

$$
(1-a) a F \Delta E_{\mathrm{p}} /(2.3 R T)
$$

Here, $a$ is a charge-transfer coefficient. $n$ the number of electron transfer. $R, T$ and $F$ symbols have their conventional meanings. $\Delta E_{\mathrm{p}}$ is the peak to peak potential separation.

The result was $1.49 \mathrm{~s}^{-1}$, which was higher than that $0.332 \mathrm{~s}^{-1}$ of the Nafion/Mb/multi-walled carbon nanotubes/carbon ionic liquid electrode (CILE) ${ }^{22}$ and $0.588 \mathrm{~s}^{-1}$ of the Co/CILE. ${ }^{23}$ Thus, the Mb-Cys-AuD bio-hybrid can provide a favorable microenvironment for $\mathrm{Mb}$ to undergo a facile electron transfer reaction for two reasons: (1) the structure of $\mathrm{AuD}$ will promote effective immobilization of enzyme, protein and other bioactive substances. Indeed, the dendrites structure greatly increased the specific surface area and offered more binding sites for the immobilization of $\mathrm{Mb}$; (2) the soft template egg white contains a lot of protein and amino acid, which provide a benign microenvironment for the assembly process.

The effect of $\mathrm{pH}$ value on the direct electrochemistry of $\mathrm{Mb}$ at the Mb-Cys-AuD/GCE was investigated. As shown in Fig. 5, the $\mathrm{pH}$ value had an obvious effect on the peak currents of the immobilized $\mathrm{Mb}$. By comparison, a better electrochemical response of the immobilized $\mathrm{Mb}$ was obtained at $\mathrm{pH}$ 7.0. This is suggested that the neutral $\mathrm{pH}$ value is close to the physiological environment and could retain activity of the $\mathrm{Mb}$ effectively. Thus, all the experiments were performed in $\mathrm{pH} 7.0$ PBS unless specially stated.

The peak potentials were also dependent on $\mathrm{pH}$ value. With the increase of $\mathrm{pH}$ value from 4.0 to 9.0 , the formal potentials $\left(E^{0^{\prime}}\right)$ shifted linearly to the negative direction (Fig. 5 inset), and the linear regression equation was obtained as $E^{0^{\prime}}(\mathrm{mV})=-0.8$ $-47.8 \mathrm{pH}, r=0.9757(n=5)$ with a slope value of $47.8 \mathrm{mV} / \mathrm{pH}$. The slope value was slightly less than the theoretically expected value of $59 \mathrm{mV} / \mathrm{pH}$ at $25^{\circ} \mathrm{C}$. One reason might be the influence

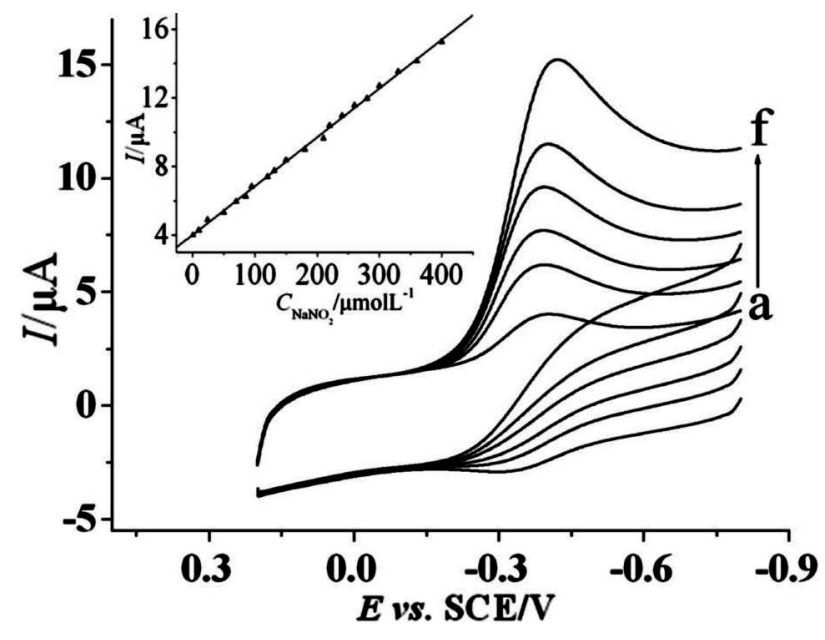

Fig. $6 \mathrm{CV}$ s of the obtained at the Mb-Cys-AuD/GCE in $\mathrm{N}_{2}$ saturated PBS with $0.5,85,130,260,400 \mu \mathrm{M} \mathrm{NO}_{2}^{-}$(from a to f), respectively. Inset: the relationship between cathodic peak current with the concentration of $\mathrm{NO}_{2}^{-}$.

of the protonation states of ligands trans to the heme iron and amino acids around the heme, or the protonation of the water molecule coordinated to the central iron. ${ }^{24}$ However, the above results still indicate that a single proton transfer accompanying one electron transfer happened in the electrochemical process of $\mathrm{Mb}$ at the Mb-Cys-AuD/GCE. The electron process can be expressed by the following equation: ${ }^{25}$

Mb-hemeFe(III) $+\mathrm{H}^{+} \longrightarrow$ Mb-hemeFe(II)

\section{Electrocatalysis of $\mathrm{Mb}$ to $\mathrm{NO}_{2}$}

The Mb-Cys-AuD/GCE exhibited good catalytic activity towards $\mathrm{NO}_{2}^{-}$. When $\mathrm{NO}_{2}{ }^{-}$was added into PBS $(0.1 \mathrm{M}, \mathrm{pH} 7.0)$, the catalytic reduction peak current at $-0.369 \mathrm{~V}$ (Fig. 6, curve a) increased (curves $b-f$ ). Meanwhile, the oxidation peak current of $\mathrm{Mb}$ was decreased. One possible mechanism of electrocatalytic reduction of $\mathrm{NO}_{2}^{-}$at $\mathrm{Mb}$-based enzyme electrode is the following: ${ }^{26}$

$$
\begin{aligned}
& \mathrm{NO}_{2}^{-}+\mathrm{H}^{+} \longrightarrow \mathrm{HNO}_{2} \\
& 3 \mathrm{HNO}_{2} \longrightarrow 2 \mathrm{NO}+\mathrm{NO}_{3}^{-}+\mathrm{H}_{2} \mathrm{O} \\
& \mathrm{Mb}\left[\mathrm{Heme}\left(\mathrm{Fe}^{3+}\right)\right]+\mathrm{H}^{+}+\mathrm{e}^{-} \longrightarrow \mathrm{Mb}\left[\mathrm{Heme}\left(\mathrm{Fe}^{2+}\right)\right] \\
& \text { at electrode } \\
& \mathrm{NO}+\mathrm{H}^{+}+\mathrm{e}^{-} \\
& \mathrm{Mb}\left[\mathrm{Heme}\left(\mathrm{Fe}^{2+}\right)\right]+\mathrm{H}_{2} \mathrm{O}+\mathrm{N}_{2} \mathrm{O} \text { at electrode }
\end{aligned}
$$

The cathodic peak current has a linear relationship with the concentration of $\mathrm{NO}_{2}{ }^{-}$in the range between $0.5-400 \mu \mathrm{M}$, as shown in the insert of Fig. 6, such a relationship which indicates the Mb-Cys-AuD/GCE can be used for the detection of $\mathrm{NO}_{2}{ }^{-}$. And the linear regression equation was $I_{\mathrm{ss}}(\mu \mathrm{A})=2.85 \times 10^{-2} \mathrm{C}$ $(\mu \mathrm{M})+4.01$, with a correlation coefficient $0.9983 \quad(n=20)$. The detection limit is estimated to be $0.3 \mu \mathrm{M}$ at a signal-to-noise ratio of 3. According to the Michaelis-Menten kinetic mechanism, 
Table 1 Comparison of analytical performances for some $\mathrm{NO}_{2}^{-}$ biosensors

\begin{tabular}{|c|c|c|c|c|}
\hline Biosensor & $\begin{array}{l}\text { Linear } \\
\text { range/ } \mu \mathrm{M}\end{array}$ & $\begin{array}{l}\text { Detection } \\
\text { limit/ } \mu \mathrm{M}\end{array}$ & $K_{\mathrm{M}}^{\mathrm{app}} / \mathrm{mM}$ & Ref. \\
\hline $\begin{array}{l}\text { Nafion/Mb/ } \\
\text { MWCNTs/CILE }\end{array}$ & $8.0-196$ & 6.0 & 11.1 & 23 \\
\hline HMS-GCE & $8.0-216$ & 0.8 & 0.72 & 29 \\
\hline $\mathrm{Mb}-\mathrm{ZnO}-\mathrm{GE}$ & $10-180$ & 4 & - & 30 \\
\hline$\{\text { Pluronic/Mb }\}_{8}-\mathrm{GCE}$ & $10-6000$ & 5 & 一 & 31 \\
\hline $\begin{array}{l}\text { Nafion/SLGnP-TPA- } \\
\mathrm{Mb} / \mathrm{GCE}\end{array}$ & $50-2500$ & 10 & - & 32 \\
\hline $\begin{array}{l}\text { GNRs@ } \mathrm{SiO}_{2}-\mathrm{Mb} / \\
\text { RTIL-solgel/GCE }\end{array}$ & $40-5000$ & 20 & 10.5 & 33 \\
\hline $\begin{array}{l}\text { Nafion-BMIMPF }_{6} / \\
\text { Mb/CILE }\end{array}$ & $100-8400$ & 50 & 1.46 & 34 \\
\hline Mb-Cys-AuD/GCE & $0.5-400$ & 0.3 & 0.2 & This work \\
\hline \multicolumn{5}{|c|}{$\begin{array}{l}\text { MWCNTs, multi-walled carbon nano-tubes; HMS, hexagonal } \\
\text { mesoporous silica; ZnO, zinc oxide; GE, graphite electrode; Pluronic, } \\
\left.\text { poly(ethylene oxide) })_{100} \text {-poly(propylene oxide) }{ }_{65} \text {-poly(ethylene oxide) }\right)_{100} \\
\text { triblock copolymer; SLGnP, single-layer graphene nanoplatelet; TPA, } \\
\text { tetrasodium 1,3,6,8-pyrenetetrasulfonic acid; GNRs@ } \mathrm{SiO}_{2} \text {, silica- } \\
\text { coated gold nanorods; RTIL, room temperature ionic liquid; } \mathrm{BMIMPF}_{6} \text {, } \\
\text { 1-butyl-3-methylimidazolium hexafluorophosphate. }\end{array}$} \\
\hline
\end{tabular}

the apparent Michaelis-Menten constant $K_{\mathrm{M}}^{\mathrm{app}}$ can be obtained from the electrochemical version of the Lineweaver-Burk equation: ${ }^{27,28}$

$$
1 / I_{\mathrm{ss}}=1 / I_{\max }+K_{\mathrm{M}}^{\mathrm{app}}\left(I_{\max } C\right)
$$

Here $I_{\mathrm{ss}}$ is the diffusion limiting current after the addition of the substrate. $C$ is the bulk concentration of the substrate, and $I_{\max }$ the maximum current measured under the saturate substrate conditions. The value of $K_{\mathrm{M}}^{\mathrm{app}}$ and $I_{\max }$ can be obtained by the slope and the intercept of the plot of the reciprocals of the steady-state current versus $\mathrm{NO}_{2}{ }^{-}$concentration. The apparent Michaelis-Menten constant $K_{\mathrm{M}}^{\text {app }}$ value was calculated to be $0.2 \mathrm{mM}$, which was much lower than the values in some previous reports. It is well-known that a low value of $K_{\mathrm{M}}^{\text {app }}$ represents a higher biological affinity of $\mathrm{Mb}$ in catalytic reaction of $\mathrm{NO}_{2}^{-}$. And, $\mathrm{Mb}$ can retain higher activity in the Mb-Cys-AuD. In Table 1, some of the analytical characteristics obtained in this work are compared with those previously reported in the literature..$^{23,29-34}$ It can be seen that the responses of the Mb-Cys-AuD/GCE are, in most cases, superior, especially the linear range and the detection limit, to the values obtained previously using the $\mathrm{NO}_{2}{ }^{-}$biosensor.

\section{Repeatability and stability of the $\mathrm{NO}_{2}^{-}$biosensor}

The stability and repeatability of the biosensor based on the Mb-Cys-AuD/GCE were studied in the linear range. The relative standard deviation (RSD) was $2.3 \%$ for seven successive measurements of $30 \mu \mathrm{M} \mathrm{O}_{2}{ }^{-}$in PBS; such values show that the proposed biosensor possessed a good repeatability. In repetitive potential scan circles, $\mathrm{CV}$ responses of the biosensor in $0.1 \mathrm{M}$ pH 7.0 $\mathrm{N}_{2}$ saturated PBS containing $100 \mu \mathrm{M} \mathrm{NO}_{2}^{-}$showed a little decrease $(2-3 \%)$. After that, the $\mathrm{CV}$ responses remain stable and the biosensor retained above $95 \%$ of its initial response after 20 cycles, indicating that the biosensor was stable. The storage stability of the biosensor was further investigated. The cathodic peak current of the Mb-CysAuD/GCE was measured using the same electrode and it retained above $95 \%$ of its initial response when after 4 weeks
Table 2 Detection results of $\mathrm{NO}_{2}^{-}$in waste water sample

\begin{tabular}{cccccc}
\hline $\begin{array}{c}\text { Sample } \\
\text { No. }\end{array}$ & $\begin{array}{c}\text { Content/ } \\
\mu \mathrm{M}\end{array}$ & $\begin{array}{c}\text { Added/ } \\
\mu \mathrm{M}\end{array}$ & $\begin{array}{c}\text { Found/ } \\
\mu \mathrm{M}\end{array}$ & $\begin{array}{c}\text { Recovery, } \\
\%\end{array}$ & RSD, \% \\
\hline 1 & 2.5 & 30 & 32.7 & 100.6 & 2.3 \\
2 & 4.1 & 30 & 34.0 & 99.7 & 3.1 \\
3 & 5.3 & 30 & 35.6 & 100.8 & 2.9 \\
\hline
\end{tabular}

The results are of average of five determinations by the biosensor.

stored at $4{ }^{\circ} \mathrm{C}$. These results displayed how good the stability of the biosensor based on the Mb-Cys-AuD/GCE was.

\section{Determination of $\mathrm{NO}_{2}^{-}$in real samples}

In order to verify the reliability of the modified electrode, we checked the $\mathrm{NO}_{2}^{-}$concentration in area 1 sample of waste water. Recovery studies were also carried out in waste water samples by using the standard addition method for the controlled trial. The determination results are summarized in Table 2 . The results were in acceptable agreement and thus the modified electrode could be used for the $\mathrm{NO}_{2}^{-}$sample analysis.

\section{Conclusions}

In this research, $\mathrm{Mb}$ was immobilized effectively into the assembled Mb-Cys-AuD bio-hybrid and a novel $\mathrm{NO}_{2}^{-}$biosensor was successfully fabricated based on the bio-hybrid with GCE as the basal electrode. The biosensor exhibited a variety of good electrochemical characteristics, including low detection limit, high catalytic ability, wide linearity and a larger electron transfer rate constant of $1.49 \mathrm{~s}^{-1}$. These advantages should be attributed to the following: (1) AuD plays an important role in facilitating the electron transfer between $\mathrm{Mb}$ and the electrode surface. The arrangment and uneven vent length structure of the $\mathrm{AuD}$ not only made $\mathrm{Mb}$ effectively immobilize, but also the $\mathrm{AuD}$ could be inserted into the structure of $\mathrm{Mb}$ as nano wire for electron transfer; (2) The self-assembly process of SH of the Cys with $\mathrm{AuD}$, followed by a coupling reaction between Cys with $\mathrm{Mb}$ for the fabrication of the biosensor, provides a good platform for the direct electrochemistry of $\mathrm{Mb}$ and $\mathrm{NO}_{2}{ }^{-}$ biosensing. The synergistic effects of Mb-Cys-AuD not only improved the electron transfer ability of our system, but also exhibited the signal amplification of nanosize materials. The present study has introduced the combination of biomaterial with syntheses of novel-shaped nanomaterials for the study of redox proteins by electrochemical methods, and such a combination offers new designs of enzymatic biosensors with potential applications in direct electrochemistry and biocatalysis. Further works derived by employing this strategy for the fabrication of novel biosensors are on our schedule.

\section{Acknowledgements}

The authors appreciate the financial support from the National Natural Science Foundation of China (No. 20875076), the Science Foundation of Northwest University (No. 09NW02), the Education Department of Shaanxi Province, China (No. 2010JK877), the NWU Doctorate Dissertation of Excellence Funds (No. 08YYB06) and the NWU Innovation Fund of Graduate Students (No. 10YZZ26). 


\section{References}

1. X. J. Zhao, Z. B. Mai, X. H. Kang, Z. Dai, and X. Y. Zou, Electrochim. Acta, 2008, 53, 4732.

2. C. Sicard, R. Brayner, J. Margueritat, M. Hémadi, A. Couté, C. Y. Mian, C. Hakib Djediat, J. Aubard, F. Fiévet, J. Livage, and T. Coradin, J. Mater. Chem., 2010, 20, 9342.

3. M. Yoshida, K. H. Roh, S. Mandal, S. Bhaskar, D. Lim, H. Nandivada, X. Deng, and J. Lahann, Adv. Mater., 2009, 21, 4920.

4. J. Shan and H. Tenhu, Chem. Commun., 2007, 44, 4580.

5. Y. Li, H. J. Schluesener, and S. Q. Xu, Gold Bull., 2010, $43,29$.

6. P. Yáñez-Sedeño and J. M. Pingarrón, Anal. Bioanal. Chem., 2005, 382, 884.

7. E. Katz and I. Willner, Angew. Chem., Int. Edit., 2004, 43, 6042.

8. I. F. Gallardo and L. J. Webb, Langmuir, 2010, 26, 18959.

9. S. F. Pang, T. Kondo, and T. Kawai, Chem. Mater., 2005, 17, 3636.

10. C. Kim, J. G. Oh, Y. T. Kim, H. Kim, and H. Lee, Electrochem. Commun., 2010, 12, 1596.

11. V. Pipich, M. Balz, S. E. Wolf, W. Tremel, and D. Schwahn, J. Am. Chem. Soc., 2008, 130, 6879.

12. A. E. Sommer, G. Fetter, P. Bosch, and O. Novelo, Polym. Adv. Technol., 2011, 22, 2638.

13. V. Lechevalier, R. Jeantet, A. Arhaliass, J. Legrand, and F. Nau, J. Food Eng., 2007, 83, 404.

14. M. A. Gabal, Mater. Lett., 2010, 64, 1887.

15. S. Maensiri, C. Masingboon, P. Laokul, W. Jareonboon, V. Promarak, P. L. Anderson, and S. Seraphin, Cryst. Growth Des., 2007, 7, 5.

16. T. O. Ahmadov, Z. Durmus, A. Baykal, and H. Kavas,
Chem. Mater. Sci., 2011, 47, 426.

17. T. A. Witten, Phys. Rev. B, 1983, 27, 5686.

18. S. L. Yang, B. F. Xu, J. Q. Zhang, X. D. Huang, J. S. Ye, and C. Z. Yu, J. Phys. Chem. C, 2010, 114, 4389.

19. W. Sun, X. Q. Li, Y. Wang, X. Li, C. Z. Zhao, and K. Jiao, Bioelectrochemistry, 2009, 75, 170.

20. L. Zhang, Q. Zhang, and J. H. Li, Biosens. Bioelectron., 2010, 26, 846 .

21. E. Laviron, J. Electroanal. Chem., 1979, 101, 19.

22. W. Sun, X. Q. Li, Y. Wang, X. Li, C. Z. Zhao, and K. Jiao, Bioelectrochemistry, 2009, 75, 170.

23. W. Sun, X. Q. Li, P. Qin, and K. Jiao, J. Phys. Chem. C, 2009, 113, 11294.

24. C. Y. Liu and J. M. Hu, Biosens. Bioelectron., 2009, 24, 2149.

25. X. Q. Liu, H. J. Li, F. Wang, S. Y. Zhu, Y. L. Wang, and G. B. Xu, Biosens. Bioelectron., 2010, 25, 2194.

26. W. J. Shan, P. L. He, and N. F. Hu, Electrochim. Acta, 2005, $51,432$.

27. R. A. Kamin and G. S. Wilson, Anal. Chem., 1980, 52, 1198.

28. F. R. Shu and G. S. Wilson, Anal. Chem., 1976, 48, 1679.

29. Z. H. Dai, X. X. Xu, and H. X. Ju, Anal. Biochem., 2004, 332, 23.

30. G. Zhao, J. J. Xu, and H. Y. Chen, Anal. Biochem., 2006, $350,145$.

31. Y. Xie, N. F. Hu, and H. Y. Liu, J. Electroanal. Chem., 2009, 630, 63.

32. R. Yue, Q. Lu, and Y. K. Zhou, Biosens. Bioelectron., 2011, 26, 4436.

33. W. L. Zhu, Y. Zhou, and J. R. Zhang, Talanta, 2009, 80, 224.

34. W. Sun, X. Q. Li, and K. Jiao, Electroanalalysis, 2009, 21, 959. 